\title{
Solvent-Mediated Eco-Friendly Synthesis and Characterization of Monodispersed Bimetallic Ag/Pd Nanocomposites for Sensing and Raman Scattering Applications
}

\author{
G. Sathiyadevi, ${ }^{1}$ B. Loganathan, ${ }^{1}$ and B. Karthikeyan ${ }^{1,2}$ \\ ${ }^{1}$ Department of Chemistry, Annamalai University, Annamalai Nagar, Tamil Nadu 608 002, India \\ ${ }^{2}$ Department of Chemistry and Biochemistry, University of Arizona, 1306 East University Boulevard, Tucson, AZ 85721, USA \\ Correspondence should be addressed to B. Karthikeyan; bkarthi_au@yahoo.com
}

Received 31 December 2013; Accepted 30 January 2014; Published 13 April 2014

Academic Editor: Nikolai Khlebtsov

Copyright (C) 2014 G. Sathiyadevi et al. This is an open access article distributed under the Creative Commons Attribution License, which permits unrestricted use, distribution, and reproduction in any medium, provided the original work is properly cited.

\begin{abstract}
The solvent-mediated eco-friendly monodispersed Ag/Pd bimetallic nanocomposites (BNCs) having thick core and thin shell have been prepared through novel green chemical solvent reduction method. Reducing solvent, dimethyl formamide (DMF) is employed for the controlled green synthesis. Characterization of the synthesized $\mathrm{Ag} / \mathrm{Pd} \mathrm{BNCs}$ has been done by $\mathrm{x}$-ray diffraction (XRD) studies, high-resolution scanning electron microscopy (HR-SEM), energy-dispersive X-ray analysis (EDX), and high-resolution transmission electron microscopy (HR-TEM) with selected area electron diffraction (SAED) pattern. The nature of the interaction of L-cysteine with Ag/Pd BNCs has been studied by using surface plasmon spectroscopy, Fourier transform-infrared spectroscopy (FT-IR), cyclic voltammetry (CV), and theoretical methods.
\end{abstract}

\section{Introduction}

Noble metallic nanocomposites are well known for their important applications in catalysis, biotechnology, bioengineering, surface-enhanced spectroscopy, textile engineering, nonlinear optical materials, water treatment, electronics, and optoelectronics [1-9]. However the advantage in tuning the physical and chemical properties using a bimetallic combination has triggered special interest in the synthesis and stabilization of the bimetallic over monometallic nanoparticles [10]. The bimetallic nanoparticles (BNPs) have either a core shell or different structures and the kind of this structure is decided by the method of the preparation and the control of bimetallic composition of nanoparticles. This is crucial to the improvement of essential properties of nanoparticle [11]. For instance, size-dependent core-shell Au-Ag BNPs at normal temperature had been reported [12]. Similarly, PtPd BNPs having core-shell structure can be synthesized in a single-step process [13]. To validate this concept many reports were available for the synthesis of BNPs. Particularly, $\mathrm{Ag} / \mathrm{Pd}$ BNCs have attracted much interest because of their superior catalytic activity in selective hydrogenation reaction [14] and the number of methods has been developed to synthesize $\mathrm{Ag} / \mathrm{Pd}$ nanoparticles as a single entity [15-17].

This study particularly deals with the synthesis of $\mathrm{Ag} / \mathrm{Pd}$ BNPs, having core-shell structure, involving green chemical reduction of their respective metal ions using DMF as a reducing solvent. Even though the synthesis of Ag nanoparticles using DMF has already been reported $[18,19]$, not much is known about the BNCs. It is also equally important to analyze the interfacial properties of the BNPs; for instance, adsorption of L-cysteine molecule on the surface of $\mathrm{Ag} / \mathrm{Pd}$ BNCs has also been taken into an account. Nanoparticles' interaction with L-cysteine was reported [20-23] as sensing of L-cysteine. Among the wide range of structural variations offered by BNPs, the core-shell structure is an important one, in which one element goes to the inner core and another forms an outer shell [24-30] and the functionalization 


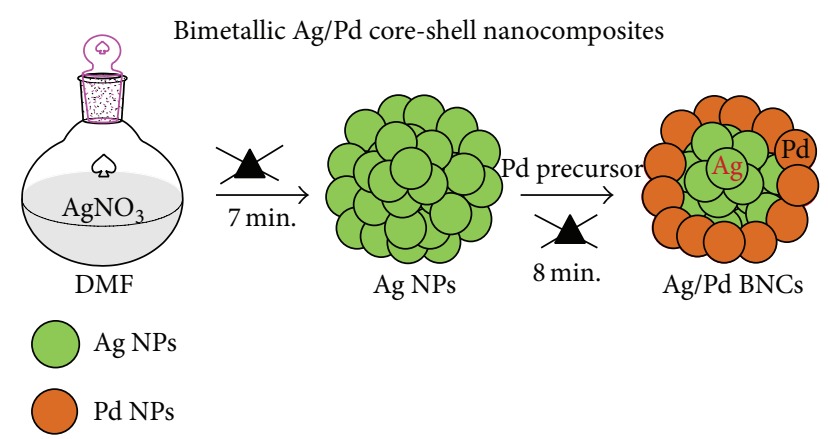

Scheme 1: Schematic representation of the synthesis of solventmediated monodispersed bimetallic Ag/Pd core-shell nanocomposites.

depends on the shell of the core-shell BNPs. By considering the above facts, $\mathrm{Ag} / \mathrm{Pd}$ core-shell nanocomposites have been synthesized and characterized; sensing and Raman scattering applications have been presented here.

\section{Experimental Section}

2.1. Materials. All chemicals used were of reagent grade and used as received. Silver nitrate $\left(\mathrm{AgNO}_{3}\right)$, palladium chloride $\left(\mathrm{PdCl}_{2}\right)$, L-cysteine $\left(\mathrm{C}_{3} \mathrm{H}_{7} \mathrm{NO}_{2} \mathrm{~S}\right)$, DMF, and distilled ethanol were purchased from Hi-Media Laboratories Pvt. Ltd. (Mumbai, India) and used as received.

2.2. Methods. Typically $0.02 \mathrm{~g}$ of $\mathrm{AgNO}_{3}$ and $50 \mathrm{~mL}$ of DMF were added to a beaker. Apparently the solution was turned to yellow from colourless indicating that the sol of $\mathrm{Ag}$ nanoparticles was formed $(7 \mathrm{~min})$. Then $0.02 \mathrm{~g}$ of $\mathrm{PdCl}_{2}$ was added to the $\mathrm{Ag}$ nanoparticles and shaken well to facilitate the formation of monodispersed $\mathrm{Ag} / \mathrm{Pd}$ core-shell BNCs (8 min). Alcoholic solution of L-cysteine was added to $\mathrm{Ag} / \mathrm{Pd} \mathrm{BNCs}$ at the time of desired spectral studies. Scheme 1 depicts the synthetic route of the synthesis of monodispersed $\mathrm{Ag} / \mathrm{Pd}$ BNCs. Synthesized sol was sonicated for $40 \mathrm{~min}$ to get fine dispersion of the nanoparticles with a "fast-clean" ultrasonic cleaner. Then, it was used for characterization studies. For surface-enhanced Raman spectroscopic (SERS) measurement, $1 \mathrm{mM}$ of L-cysteine solution was used. The Lcysteine solution was added to as-synthesized sol at the time of desired spectral analysis.

2.3. Characterization. UV-vis (ultraviolet and visible light) absorbance spectra were recorded over a range of 800$200 \mathrm{~nm}$ with a Shimadzu UV-1650 PC spectrophotometer, operated at a resolution of $0.5 \mathrm{~nm}$. The samples were filled in a quartz cuvette of $1 \mathrm{~cm}$ light-path length, and the light absorption spectra were given in reference to DMF.

Fourier transform-infrared spectra (FT-IR) were recorded using AVATAR 330 FT-IR spectrometer in $\mathrm{KBr}$ pellet.

Wide-angle powder X-ray diffraction (XRD) pattern was recorded with XPERT-PRO diffractometer equipped with

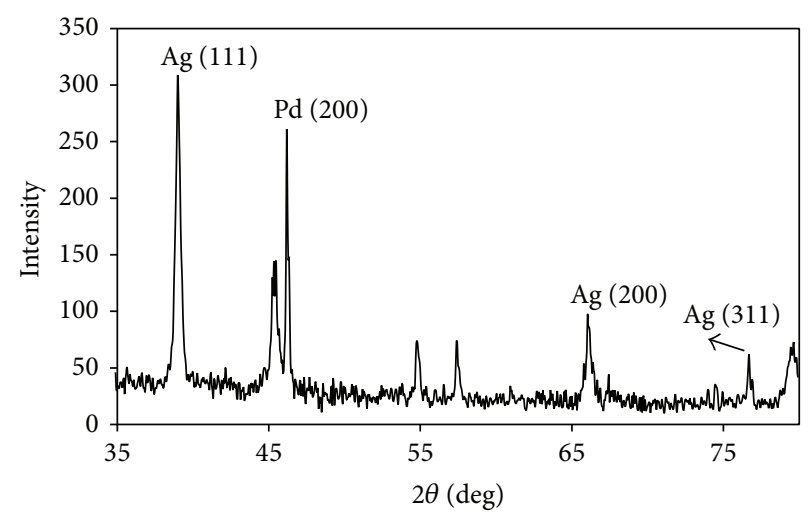

FIGURE 1: X-ray diffraction (XRD) pattern of solvent-mediated monodispersed bimetallic Ag/Pd core-shell nanocomposites.

monochromatic $\mathrm{Cu} \mathrm{K} \alpha$ radiation by using a single-step scan program.

The morphology of the colloidal sample was examined using a JEOL 3010 high-resolution transmission electron microscope (HR-TEM), with an ultra-high-resolution (UHR) pole piece operating at an accelerating voltage of $300 \mathrm{kV}$ and FEI Quanta FEG 200 high-resolution scanning electron microscope (HR-SEM), with an energy-dispersive Xray (EDX) accessory operating at an accelerating voltage of $30 \mathrm{kV}$. Sample for HR-TEM characterization was prepared by depositing a drop of the colloid on a carbon-coated $\mathrm{Cu}$ grid and allowing it to evaporate.

FT-Raman spectra were recorded with an integral microscope Raman system RFS 27 spectrometer equipped with $1024 \times 256$ pixels liquefied nitrogen-cooled germanium detector. The $1064 \mathrm{~nm}$ line of the Nd: YAG laser (red laser) was used to excite the Raman spectra. Each spectrum was recorded with an acquisition time of $18 \mathrm{sec}$. The synthesized bimetallic sol was activated by the addition of $2 \mathrm{M}$ sodium chloride to promote the aggregation.

2.4. Electrochemical Investigations. Cyclic voltammograms (CVs) were performed by using CHI $604 \mathrm{C}$ electrochemical work station. A standard three-electrode system was used to contain $\mathrm{Ag} / \mathrm{AgCl}$ reference electrode, a platinum wire as an auxiliary electrode, and the modified glassy carbon electrode (GCE) as the working electrode. Before the experiment, the GCE was polished with 1 micron alpha alumina powder, 0.3 micron alpha alumina powder, and 0.05 micron gamma alumina powder. About $1 \mathrm{~mL}$ of $\mathrm{Ag} / \mathrm{Pd}$ BNCs was added to a beaker containing $1 \mathrm{~mL}$ of distilled ethanol and sonicated for about $20 \mathrm{~min}$. Subsequently the mixture was pipetted out onto the surface of GCE by using capillary tube and allowed to dry for $30 \mathrm{~min}$ at room temperature, with the simultaneous evaporation of residual ethanol, and a secondary membrane of Nafion perfluorinated ion-exchange resin was coated onto the GCE surface and then dried to $15 \mathrm{~min}$. Thus the coated Nafion membrane helps the loaded sol to stick to the electrode surface and works as a proton exchange membrane. 
TABLE 1: Crystalline size and identification of monodispersed Ag/Pd BNCs.

\begin{tabular}{lccccc}
\hline S. number & $2 \theta\left(^{\circ}\right)$ & $d$ spacing $(\AA)$ & FWHM & Miller's indices & Crystalline size $(\mathrm{nm})$ \\
\hline 1 & 38.98 & 2.3085 & 0.41 & $111(\mathrm{Ag})$ & 3.83 \\
2 & 45.35 & 1.9980 & 0.44 & $200(\mathrm{Pd})$ & 4.26 \\
3 & 66.07 & 1.4131 & 0.35 & $200(\mathrm{Ag})$ & 6.64 \\
4 & 76.67 & 1.2419 & 0.15 & $311(\mathrm{Ag})$ & 8.11 \\
\hline
\end{tabular}

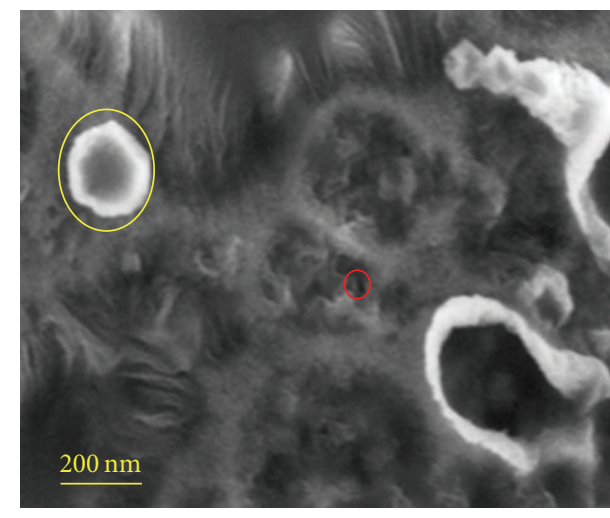

(a)

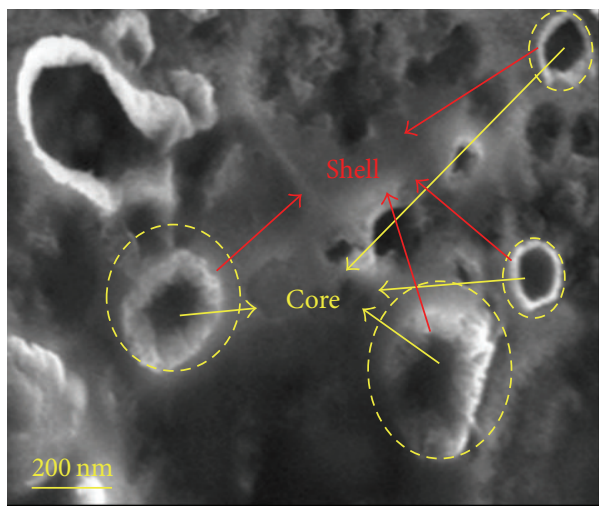

(c)

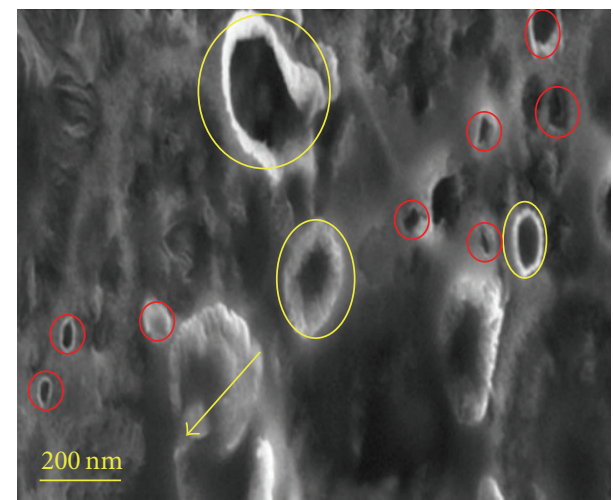

(b)

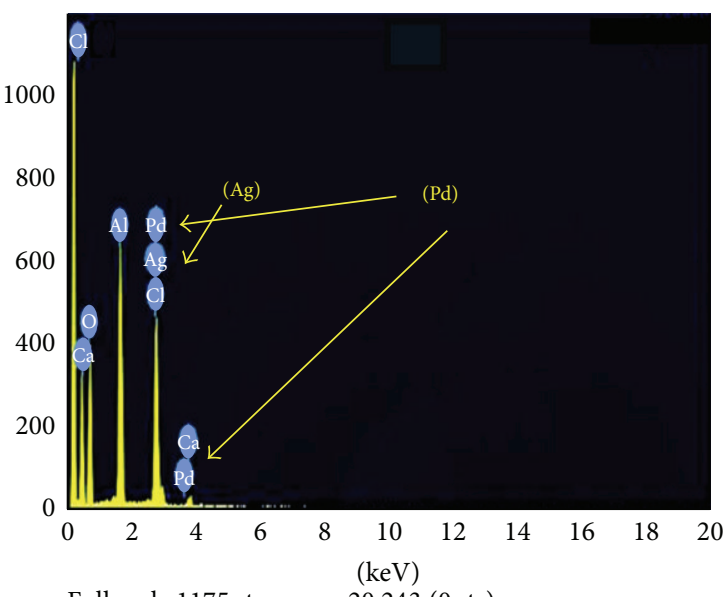

Full scale 1175 cts cursor 20.243 (0 cts)

(d)

FIgURE 2: ((a)-(c)) The high-resolution scanning electron microscopy (HR-SEM) images of bimetallic Ag/Pd core-shell nanocomposites. Scale bars: ((a)-(c)) $200 \mathrm{~nm}$. (d) Energy-dispersive X-ray (EDX) elemental mapping of bimetallic Ag/Pd core-shell nanocomposites.

All electrocatalytic solutions were deaerated with nitrogen atmosphere before performing the CV measurements.

2.5. Theoretical Calculations. The density functional calculation (DFT) presented here was performed with the Gaussian-03 W program on a Pentium (IV) computer system. The molecular geometry of L-cysteine-Pd surface complex model was optimized using the method B3LYP with the basis set of Lanl2DZ. A complete geometry optimization was carried out employing Berny's optimization algorithm, which resulted in CS symmetry. The vibrational frequencies and the corresponding normal modes were then evaluated at the optimized geometry using analytical differentiation algorithms contained within the program.

\section{Results and Discussion}

3.1. X-Ray Diffraction (XRD) Analysis. Figure 1 depicts the XRD pattern of the solvent-mediated monodispersed $\mathrm{Ag} / \mathrm{Pd}$ BNCs. The XRD showed a diffraction at $2 \theta=45.35^{\circ}$ (sharp). It suggests that the prepared BNCs were small-sized and of face-centered cubic (fcc) structure. The reflection peaks 


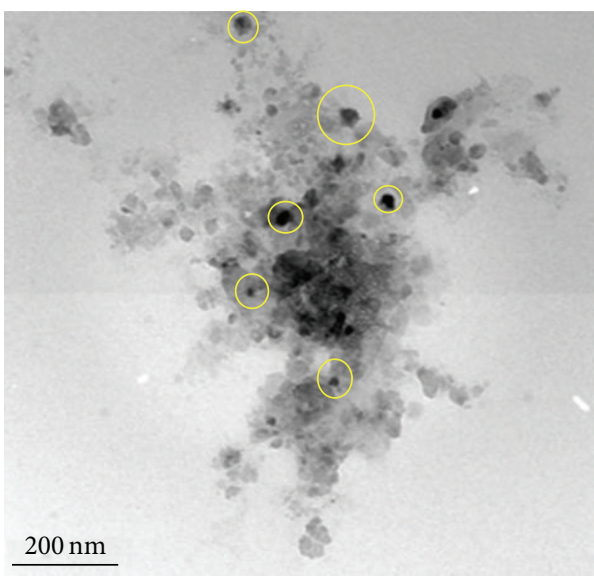

(a)

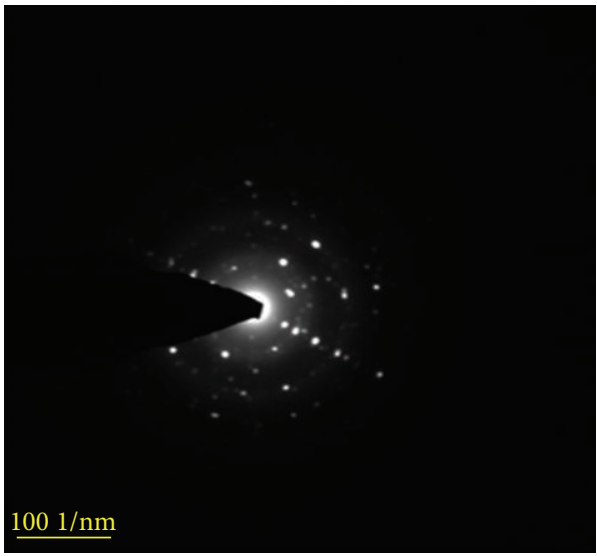

(c)

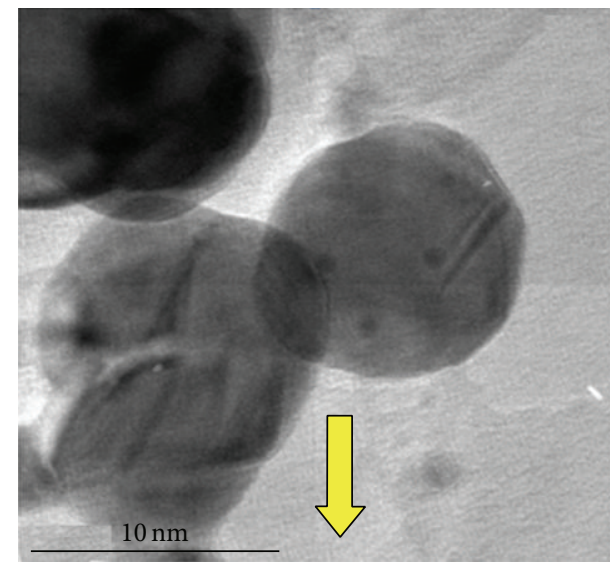

(b)

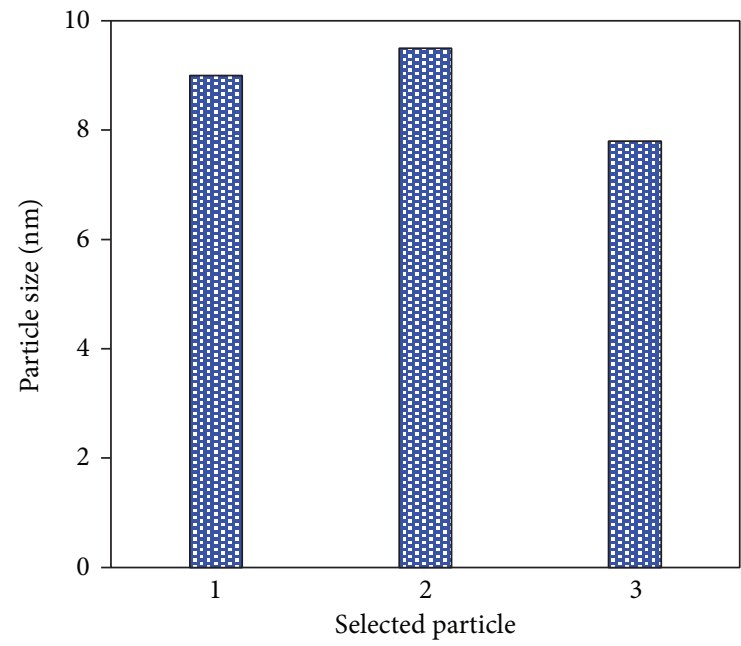

(d)

FIGURE 3: ((a)-(b)) High-resolution transmission electron microscopy (HR-TEM) images of bimetallic Ag/Pd core-shell nanocomposites. Scale bars: (a) $200 \mathrm{~nm}$, (b) $10 \mathrm{~nm}$. (c) Selected area electron diffraction(SAED) pattern of bimetallic Ag/Pd core-shell nanocomposites. (d) Particle size distribution histogram of bimetallic Ag/Pd core-shell nanocomposites.

appeared at $2 \theta=38.98^{\circ}, 45.19^{\circ}, 66.07^{\circ}$, and $76.67^{\circ}$ ascribed

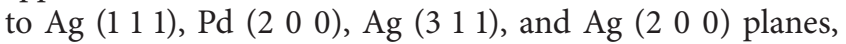
respectively. The sizes of BNCs were calculated by using Scherrer's equation $[26,28,29]$ and were found to be $~$ $6 \mathrm{~nm}$ in size. Table 1 shows the calculated size of crystalline nanoparticles and the identified crystal planes.

\subsection{High-Resolution Scanning Electron Microscopy (HR-SEM)} and Energy-Dispersive X-Ray (EDX) Spectroscopic Analysis. Figure 2 represents the HR-SEM images and EDX analysis of the solvent-mediated monodispersed bimetallic Ag/Pd coreshell nanocomposites. The core-shell thin-shell-like structure of the synthesized $\mathrm{Ag} / \mathrm{Pd} \mathrm{BNCs}$ is clearly visible in Figures 2(a)-2(c). The EDX analysis (Figure 2(d)) of Ag/Pd BNCs reveals a higher concentration of palladium on the surface suggesting the formation of Pd shell (70\% of Pd by weight and core of about $30 \%$ of Ag by weight).
3.3. High-Resolution Transmission Electron Microscopic (HRTEM) Analysis. HR-TEM images of the solvent-mediated monodispersed bimetallic Ag/Pd core-shell nanocomposites are shown in Figure 3, along with the particle size distribution histogram. Successive reduction strategy yields highly uniform monodispersed spherical core-shell BNCs (Figures 3(a)-3(b)). The size distributions were very narrow as shown in the histogram (Figure $3(\mathrm{c})$ ). The SAED pattern (Figure 3(d)) reveals the diffraction rings from core to shell which are indexed as (1 111$),\left(\begin{array}{lll}2 & 0 & 0\end{array}\right),\left(\begin{array}{lll}2 & 0 & 0\end{array}\right)$, and (3 111$)$ confirming the fcc structure of Ag/Pd BNCs.

3.4. UV-Visible Spectral Studies. The absorption spectrum of solvent-mediated monodispersed bimetallic Ag/Pd coreshell nanocomposites exhibits a clear single absorbance at $482 \mathrm{~nm}$ (Figure 4(a)). Furthermore the addition of L-cysteine reduced the intensity of surface plasmon with respect to time 


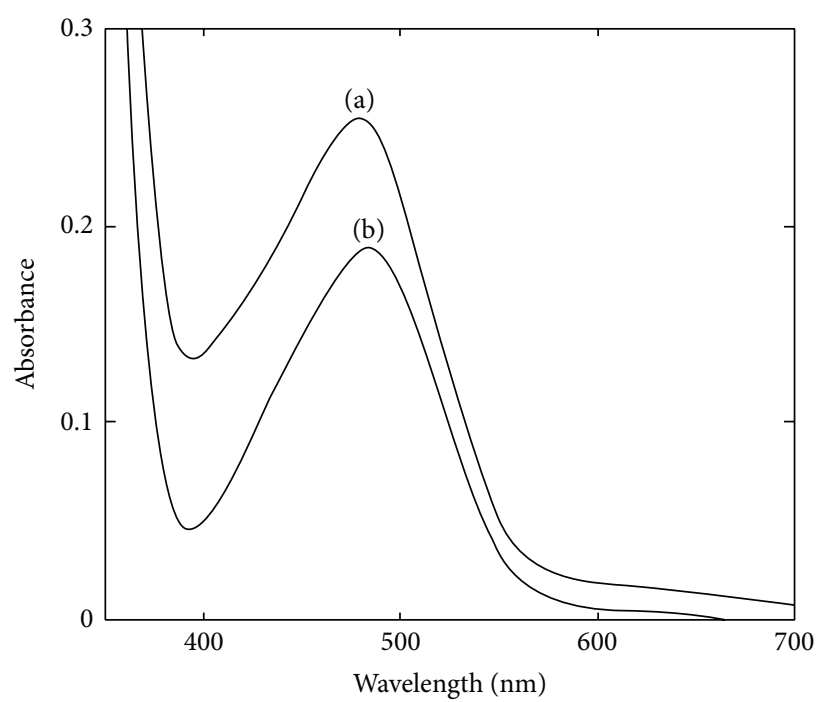

Figure 4: (a) UV-visible absorption spectrum of bimetallic Ag/Pd core-shell nanocomposites and (b) absorption of L-cysteine on bimetallic $\mathrm{Ag} / \mathrm{Pd}$ core-shell nanocomposites.

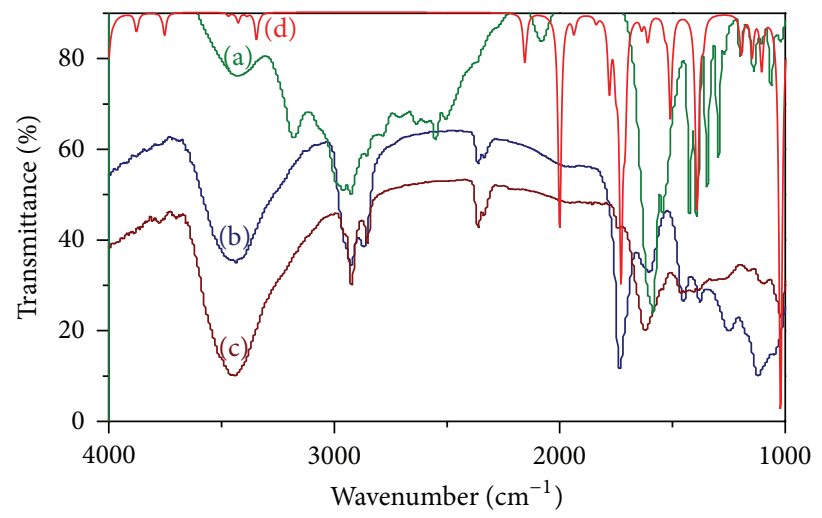

FIGURE 5: (a) Fourier transmission-infrared (FT-IR) spectrum of L-cysteine, (b) L-cysteine adsorbed Ag/Pd core-shell nanocomposites, (c) $\mathrm{Ag} / \mathrm{Pd} \mathrm{BNCs}$, and (d) computed FT-IR spectrum of the L-cysteine-Pd surface complex.

and the observed red shift is ascribed to the aggregation of BNCs in the presence of L-cysteine (Figure 4(b)). From the above observations it is concluded that the L-cysteine molecules are functionalized on the BNCs surface. This phenomenon was used for the further preparation of Lcysteine functionalized of $\mathrm{Ag} / \mathrm{Pd}$ core-shell nanocomposites.

3.5. Fourier Transform-Infrared (FT-IR) Analysis. The vibrational features of L-cysteine adsorbed Ag/Pd core-shell BNCs were examined by comparing FT-IR spectrum of L-cysteine (Figure 5(a)), L-cysteine adsorbed Ag/Pd BNCs (Figure 5(b)), and only Ag/Pd BNCs (Figure 5(c)). When $\mathrm{L}$-cysteine molecule attached to the surface of free BNCs, the vibrational frequencies originating from the functional groups of L-cysteine were expected to shift accordingly. In L-cysteine, the important stretching vibrational modes are assigned as follows: $-\mathrm{NH}$ stretching $\left(3180 \mathrm{~cm}^{-1}\right)$, symmetric stretching vibration of $-\mathrm{CH}\left(2964 \mathrm{~cm}^{-1}\right),-\mathrm{SH}\left(2554 \mathrm{~cm}^{-1}\right)$, and $-\mathrm{NH}$ bending vibration $\left(1587 \mathrm{~cm}^{-1}\right)$. The $-\mathrm{SH}$ stretching in the L-cysteine is found to be absent in the $\mathrm{Ag} / \mathrm{Pd}-\mathrm{L}-$ cysteine surface complex which indicates the attachment of$\mathrm{SH}$ group of L-cysteine on the surface of $\mathrm{Ag} / \mathrm{Pd}$ core-shell BNCs. The assignments were made by the computed IR spectrum of the L-cysteine-Pd surface complex (Figure 5(d)) theoretical model (Figure 6). The possible assignments of FTIR frequencies of L-cysteine and L-cysteine functionalized $\mathrm{Ag} / \mathrm{Pd} \mathrm{BNCs}$ along with their computed vibrational frequencies are compiled in Table 2.

3.6. Cyclic Voltammetry-Electrochemical Sensing. Figure 7 represents cyclic voltammograms of L-cysteine at the Ag$\mathrm{Pd} / \mathrm{GCE}$ in $0.1 \mathrm{M} \mathrm{KCl}$ recorded in the absence (curve a) and 
TABLE 2: The possible assignments of FT-IR frequencies of L-cysteine and L-cysteine functionalized Ag/Pd BNCs along with their computed vibrational frequencies $\left(\mathrm{cm}^{-1}\right)$.

\begin{tabular}{|c|c|c|c|}
\hline $\begin{array}{l}\text { FT-IR frequencies of } \\
\text { L-cysteine }\left(\mathrm{cm}^{-1}\right)\end{array}$ & $\begin{array}{l}\text { Computed vibrational } \\
\text { frequencies }\left(\mathrm{cm}^{-1}\right)\end{array}$ & $\begin{array}{c}\text { L-cysteine functionalized } \\
\text { Ag/Pd BNPs }\left(\mathrm{cm}^{-1}\right)\end{array}$ & Possible assignments \\
\hline 538 & 591 & - & CC str \\
\hline 637 & - & 607 & CS str \\
\hline 692 & 670 & 670 & CS str \\
\hline 821 & 853 & 803 & $\mathrm{CO}_{2}$ bend \\
\hline- & 916 & 954 & CC sym \\
\hline 1008 & - & 1011 & $\mathrm{NH}_{2}$ bend \\
\hline 1063 & 1097 & 1100 & $\mathrm{CN}$ str \\
\hline 1203 & 1202 & 1201 & $\mathrm{CH}_{2}$ str \\
\hline 1296 & 1226 & 1247 & $\mathrm{CH}_{2}$ wagg \\
\hline 1346 & - & 1355 & $\mathrm{CO}_{2}$ str \\
\hline 1393 & 1395 & 1399 & $\mathrm{COO}^{-}$str \\
\hline 1423 & 1401 & 1414 & $\mathrm{CH}_{2}$ bend \\
\hline 1587 & 1594 & - & NH bend \\
\hline 2554 & - & - & SH str \\
\hline 2964 & - & - & $\mathrm{CH}$ sym.str \\
\hline 3180 & 3205 & 3235 & $\mathrm{NH}$ str \\
\hline 3430 & 3435 & 3488 & $\mathrm{OH}$ str \\
\hline
\end{tabular}

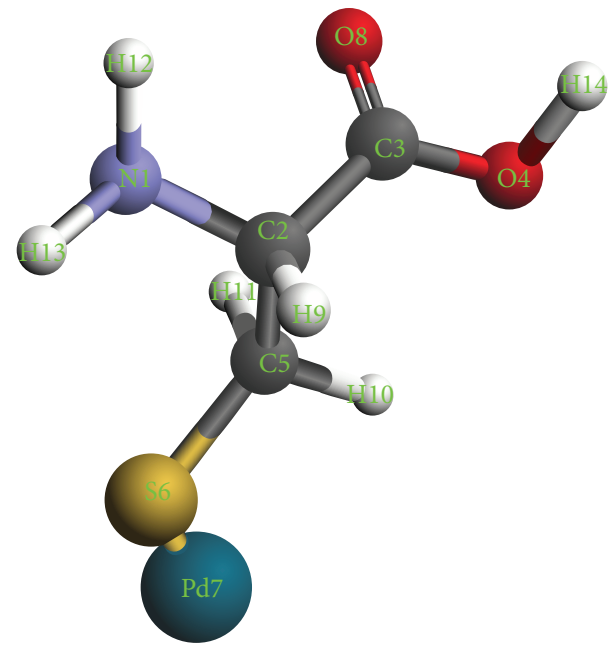

FIgURE 6: L-cysteine-Pd surface complex model.

presence (curve b) of $0.2 \mathrm{M} \mathrm{L}$-cysteine at the scan rate of $50 \mathrm{mVs}^{-1}$. A well-defined anodic peak at $0.68 \mathrm{~V}$ in the $\mathrm{CV}$ is attributed to the L-cysteine oxidation. There is no reduction peak in the reverse scan of the potential window -0.2 to $0.1 \mathrm{~V}$ revealing that the process is chemically irreversible. Electrooxidation of L-cysteine involves a strong interaction of the sulphur atom with an active site on the electrode surface having noble metals [31]. This observation further confirmed that the L-cysteine functionalizes on the surface of $\mathrm{Ag} / \mathrm{Pd} \mathrm{BNCs}$. The enhancement of anodic current may be taken as electrochemical sensing of L-cysteine. The detailed mechanism and limitations were discussed elsewhere.

3.7. Raman Scattering. The Raman spectrum of L-cysteine and the SERS of L-cysteine adsorbed on BNCs are given in Figure 8. Frequencies were shifted and showed variable intensities with the normal Raman spectrum. C-S frequency can be assigned to $665 \mathrm{~cm}^{-1}$, where this mode is assigned at $690 \mathrm{~cm}^{-1}$ in the solution. But in SERS C-S frequency is located at $696 \mathrm{~cm}^{-1}$. This shift indicates that the sulphur atom of L-cysteine may be directly bonded to the Pd metal. Another aspect in the SERS spectrum is the absence of S-H stretching vibration frequency, which appears at $2554 \mathrm{~cm}^{-1}$ in the normal Raman spectrum, indicating the definite involvement of the sulphur atom.

\section{Conclusion}

Solvent-mediated eco-friendly monodispersed bimetallic $\mathrm{Ag} / \mathrm{Pd}$ core-shell nanocomposites were successfully synthesized using DMF without any form of heating, a solvent which facilitates the formation of monodispersed BNCs. The BNCs were characterized by techniques such as XRD, HR-SEM, EDX, and HR-TEM. The obtained results confirmed that the as-synthesized BNCs possess a core shell having thick core and thin shell structure. The adsorption of L-cysteine on the bimetallic core-shell surface was ascertained by using FT-IR, Raman, UV-visible, CV, and DFT calculations. The present study showed the synthesis of Ag/Pd core-shell BNCs by the solvent controlled green reduction and the L-cysteine functionalised BNCs. 


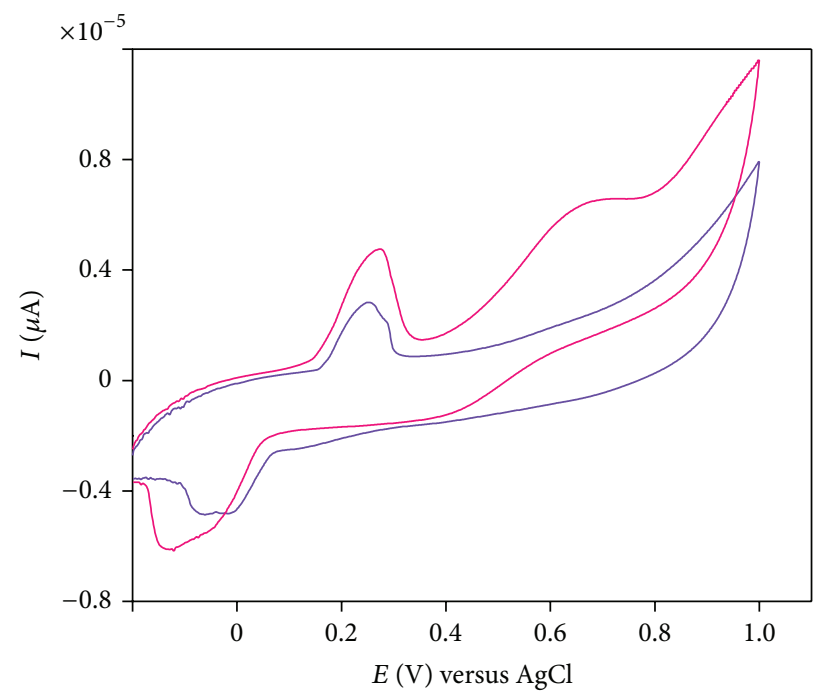

(a) Ag-Pd/GCE (KCl)

(b) Ag-Pd/GCE (KCl + L-cysteine)

Figure 7: (a) Cyclic voltammogram (CV) of bimetallic Ag/Pd core-shell nanocomposites loaded on GCE and (b) CV of bimetallic Ag/Pd core-shell nanocomposites loaded on GCE in the presence of L-cysteine $(2 \mathrm{~mL})$.

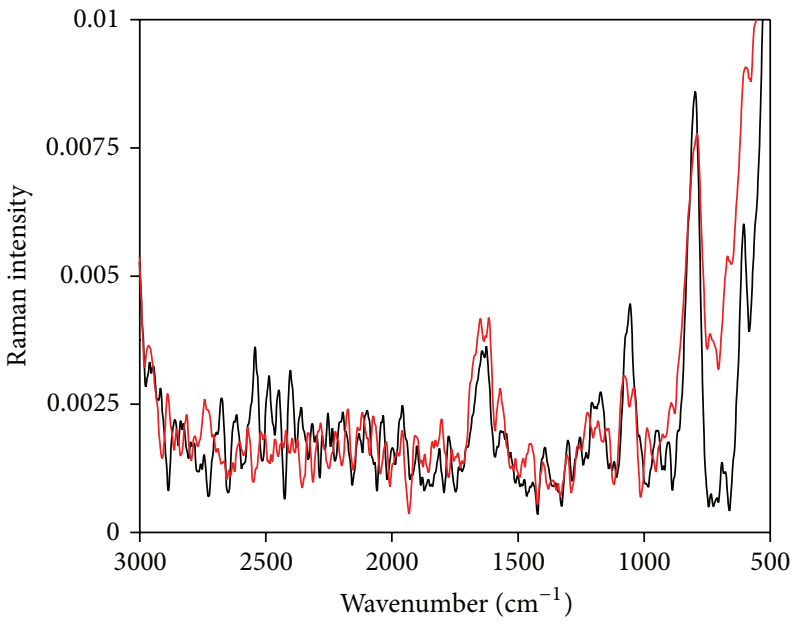

(a) $0.001 \mathrm{M}$ of L-cysteine

(b) SERS of Ag/Pd BNCs

FIGURE 8: (a) Raman spectrum of $1 \mathrm{mM}$ of aqueous L-cysteine and (b) surface-enhanced Raman scattering (SERS) of $1 \mathrm{mM}$ of L-cysteine adsorbed on Ag/Pd BNCs.

\section{Abbreviations}

BNCs: Bimetallic nanocomposites

BNPs: Bimetallic nanoparticles

DMF: Dimethyl formamide.

\section{Conflict of Interests}

The authors declare no competing financial interests.

\section{Acknowledgments}

Electron microscopy was performed at the National Centre for Nanoscience and Nanotechnology, University of Madras. XRD data were recorded at the Department of Physics, Alagappa University, Karaikudi, India. SERS data were performed at Sophisticated Analytical Instrument Facility (SAIF), Indian Institute of Technology (IIT) Madras. For HRSEM and HR-TEM images, the authors are highly thankful to 
Dr. S. Sriman Narayanan, Professor of Analytical Chemistry, University of Madras. B. Loganathan wishes to acknowledge the University Grants Commission (UGC)-Basic Sciences Research (BSR)-Special Assistant Programme (SAP) Fellowship from the UGC, New Delhi, India.

\section{References}

[1] C. Tamuly, M. Hazarika, S. C. Borah, M. R. Das, and M. P. Boruah, "In situ biosynthesis of $\mathrm{Ag}, \mathrm{Au}$ and bimetallic nanoparticles usingPiper pedicellatumC.DC: green chemistry approach," Colloids and Surfaces B: Biointerfaces, vol. 102, pp. 627-634, 2013.

[2] J. E. Hutchison, T. A. Postlethwaite, and R. W. Murray, "Molecular films of thiol-derivatized tetraphenylporphyrins on gold: film formation and electrocatalytic dioxygen reduction," Langmuir, vol. 9, no. 11, pp. 3277-3283, 1993.

[3] B. Karthikeyan, "Optical studies on thermally surface plasmon tuned $\mathrm{Au}, \mathrm{Ag}$ and $\mathrm{Au}: \mathrm{Ag}$ nanocomposite polymer films," Spectrochimica Acta A: Molecular and Biomolecular Spectroscopy, vol. 96, pp. 456-460, 2012.

[4] M. Pavlin and V. B. Bregar, "Stability of nanoparticle suspensions in different biologically relevant media," Digest Journal of Nanomaterials and Biostructures, vol. 7, no. 4, pp. 1389-1400, 2012.

[5] S. D. Oh, B. K. So, S. H. Choi et al., "Dispersing of Ag, Pd, and $\mathrm{Pt}-\mathrm{Ru}$ alloy nanoparticles on single-walled carbon nanotubes by gamma-irradiation," Materials Letters, vol. 59, no. 10, pp. 11211124, 2011.

[6] B. Karthikeyan and B. Loganathan, "A close look of Au/Pt/Ag nanocomposites using SERS assisted with optical, electrochemical, spectral and theoretical methods," Physica E: LowDimensional Systems and Nanostructures, vol. 49, pp. 105-110, 2013.

[7] B. Loganathan and B. Karthikeyan, "Au core $\mathrm{Pd} / \mathrm{Pt}$ shell in trimetallic $\mathrm{Au} / \mathrm{Pd} / \mathrm{Pt}$ colloidal nanocomposites: physicochemical characterization study," Colloids and Surfaces A: Physicochemical and Engineering Aspects, vol. 436, pp. 944-952, 2013.

[8] A. I. Ryasnyanskiy, B. Palpant, S. Debrus, U. Pal, and A. L. Stepanov, "Optical nonlinearities of Au nanoparticles embedded in a zinc oxide matrix," Optics Communications, vol. 273, no. 2, pp. 538-543, 2007.

[9] T. A. Postlethwaite, J. E. Hutchison, K. W. Hathcock, and R. W. Murray, "Optical, electrochemical, and electrocatalytic properties of self-assembled thiol-derivatized porphyrins on transparent gold films," Langmuir, vol. 11, no. 10, pp. 4109-4116, 1995.

[10] L. D'Souza, P. Bera, and S. Sampath, "Silver-palladium nanodispersions in silicate matrices: highly uniform, stable, bimetallic structures," Journal of Colloid and Interface Science, vol. 246, no. 1, pp. 92-99, 2002.

[11] K. Patel, S. Kapoor, D. P. Dave, and T. Mukherjee, "Synthesis of $\mathrm{Pt}, \mathrm{Pd}, \mathrm{Pt} / \mathrm{Ag}$ and $\mathrm{Pd} / \mathrm{Ag}$ nanoparticles by microwave-polyol method," Journal of Chemical Sciences, vol. 117, no. 4, pp. 311-316, 2005.

[12] T. Shibata, B. A. Bunker, Z. Zhang, D. Meisel, C. F. I. Vardeman, and J. D. Gezelter, "Size-dependent spontaneous alloying of AuAg nanoparticles," Journal of the American Chemical Society, vol. 124, no. 40, pp. 11989-11996, 2002.
[13] L. D'Souza and S. Sampath, "Preparation and characterization of silane-stabilized, highly uniform, nanobimetallic Pt-Pd particles in solid and liquid matrixes," Langmuir, vol. 16, no. 22, pp. 8510-8517, 2000.

[14] X. Wu, Y. Wu, X. Kai, G. Wu, and Y. Chen, "Structural optimization of Ag-Pd clusters based on different potential parameterizations," Chemical Physics, vol. 390, pp. 36-41, 2011.

[15] R. Redon, S. K. R. Lara, A. L. F. Osorio, and V. M. U. Saldivar, "Aerobic synthesis of palladium nanoparticles," Reviews on Advanced Materials Science, vol. 27, no. 1, pp. 31-42, 2011.

[16] S. Panigrahi, S. Kundu, S. K. Guosh, S. Nath, and T. Pal, "General method of synthesis for metal nanoparticles," Journal of Nanoparticle Research, vol. 6, no. 4, pp. 411-414.

[17] S. R. Boddu, V. R. Gutti, T. K. Ghosh, R. V. Tompson, and S. K. Loyalka, "Gold, silver, and palladium nanoparticle/nanoagglomerate generation, collection, and characterization," Journal of Nanoparticle Research, vol. 13, no. 12, pp. 6591-6601, 2011.

[18] I. P. Santos and L. M. L. Marzan, "Reduction of silver nanoparticles in DMF: formation of monolayers and stable colloids," Pure and Applied Chemistry, vol. 72, no. 1-2, pp. 83-90, 2000.

[19] I. Pastoriza-Santos and M. Liz-Marzán, "Formation and stabilization of silver nanoparticles through reduction by N,Ndimethylformamide," Langmuir, vol. 15, no. 4, pp. 948-951, 1999.

[20] E. Sharifi, A. Salimi, and E. Shams, "DNA/nickel oxide nanoparticles/osmium(III)-complex modified electrode toward selective oxidation of l-cysteine and simultaneous detection of 1-cysteine and homocysteine," Bioelectrochemistry, vol. 86, pp. 9-21, 2012.

[21] Y. Song, Y.-Z. Song, A.-F. Zhu, and H. Zhong, "L-cysteinenano-gold modified glassy carbon electrode and its application for determination of dopamine hydrochloride," Indian Journal of Chemistry A: Inorganic, Physical, Theoretical and Analytical Chemistry, vol. 50, no. 7, pp. 1006-1009, 2011.

[22] A. Pawlukojć, J. Leciejewicz, A. J. Ramirez-Cuesta, and J. Nowicka-Scheibe, "L-Cysteine: neutron spectroscopy, Raman, IR and ab initio study," Spectrochimica Acta A: Molecular and Biomolecular Spectroscopy, vol. 61, no. 11-12, pp. 2474-2481, 2005.

[23] S. Aryal, B. K. C. Remant, N. Dharmaraj, N. Bhattarai, C. H. Kim, and H. Y. Kim, "Spectroscopic identification of SAu interaction in cysteine capped gold nanoparticles," Spectrochimica Acta A: Molecular and Biomolecular Spectroscopy, vol. 63, no. 1, pp. 160-163, 2006.

[24] K. Kim, K. L. Kim, and K. S. Shin, "Co-reduced Ag/Pd bimetallic nanoparticles: surface enrichment of Pd revealed by Raman spectroscopy," Journal of Physical Chemistry C, vol. 115, no. 30, pp. 14844-14851, 2011.

[25] B. Karthikeyan and M. Murugavelu, "Nano bimetallic Ag/Pt system as efficient opto and electrochemical sensing platform towards adenine," Sensors and Actuators B: Chemical, vol. 163, no. 1, pp. 216-223, 2012.

[26] B. Karthikeyan and B. Loganathan, "Strategic green synthesis and characterization of $\mathrm{Au} / \mathrm{Pt} / \mathrm{Ag}$ trimetallic nanocomposites," Materials Letters, vol. 85, pp. 53-56, 2012.

[27] D. Jose and B. R. Jagirdar, "Ag@Pd core-shell nanoparticles," Indian Journal of Chemistry A: Inorganic, Physical, Theoretical and Analytical Chemistry, vol. 50, no. 9-10, pp. 1308-1317, 2011.

[28] K. Deplanche, M. L. Merroun, M. Casadesus et al., "Microbial synthesis of core/shell gold/palladium nanoparticles for applications in green chemistry," Journal of the Royal Society Interface, vol. 9, pp. 1705-1712, 2012. 
[29] B. Karthikeyan and B. Loganathan, "Rapid green synthetic protocol for novel trimetallic nanoparticles," Journal of Nanoparticles, Article ID 168916, 8 pages, 2013.

[30] D. S. Sheny, J. Mathew, and D. Philip, "Phytosynthesis of Au, $\mathrm{Ag}$ and $\mathrm{Au}-\mathrm{Ag}$ bimetallic nanoparticles using aqueous extract and dried leaf of Anacardium occidentale," Spectrochimica Acta A: Molecular and Biomolecular Spectroscopy, vol. 79, no. 1, pp. 254-262, 2011.

[31] Z. Samec, Z. Malysheva, J. Koryta, and J. Pradáć, "A contribution to the voltammetric study of cystine and cysteine at Pt electrodes in $0.5 \mathrm{M} \mathrm{H}_{2} \mathrm{SO}_{4}$," Journal of Electroanalytical Chemistry, vol. 65, no. 2, pp. 573-586, 1975. 

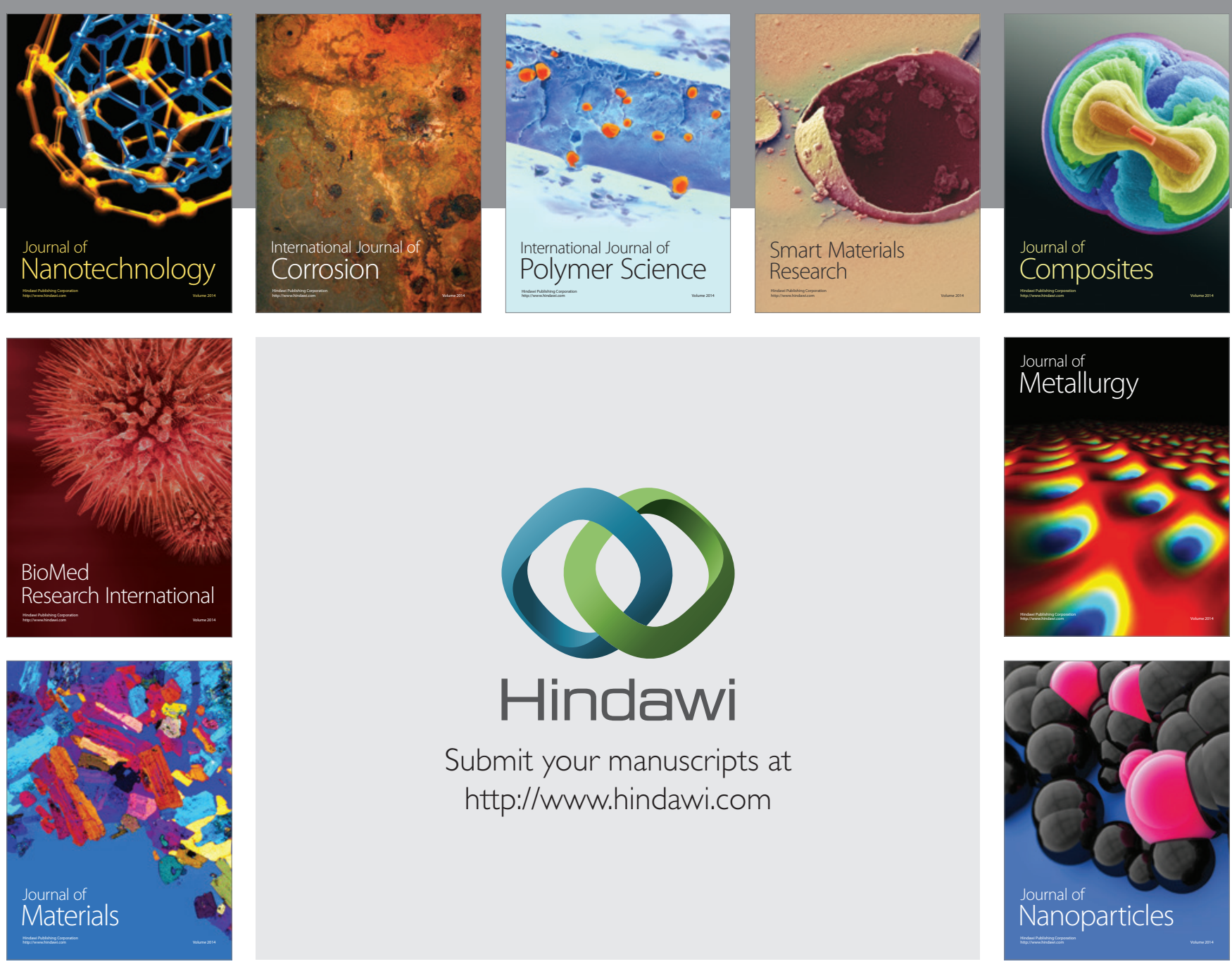

Submit your manuscripts at http://www.hindawi.com
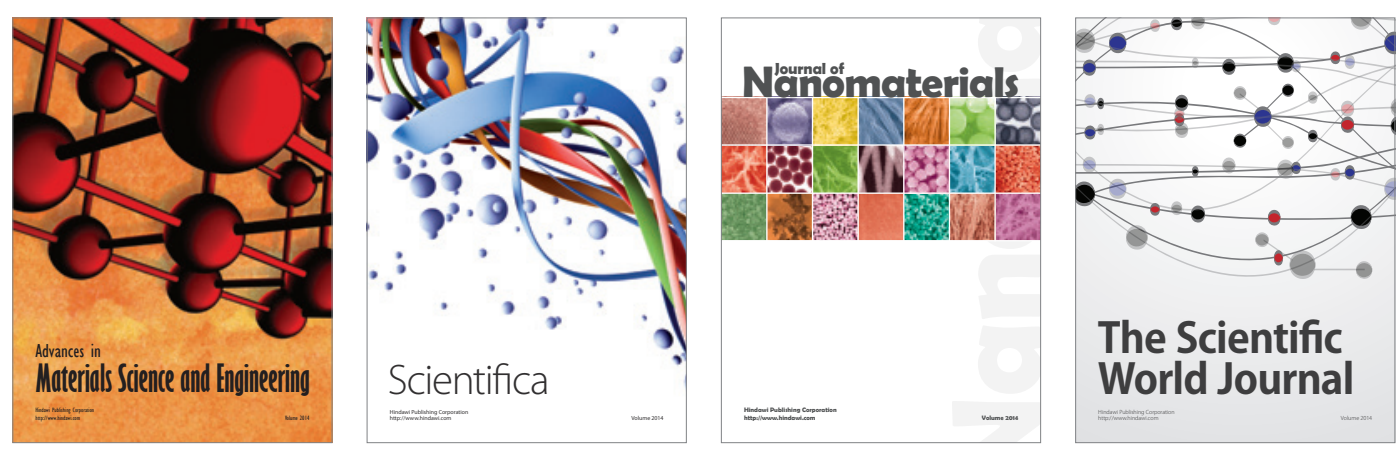

\section{The Scientific World Journal}
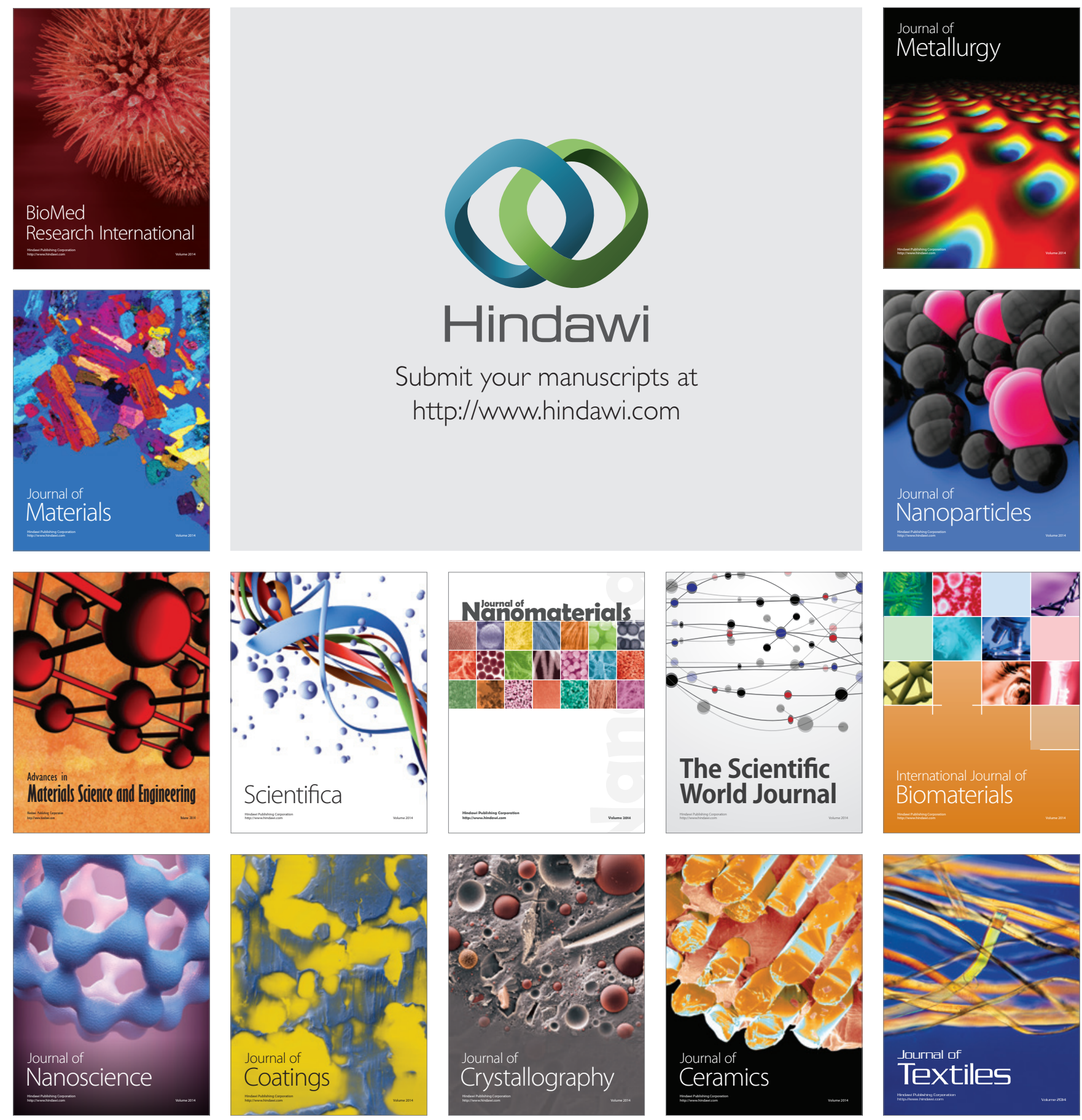